\title{
Sporda Sürdürülebilir Başarı İçin Beden Eğitimi Öğretmenleri Bakış Açısı
}

\author{
Tayfun ŞİRINN ${ }^{1}$, Enver DÖŞYILMAZ ${ }^{2}$ ve Yeliz ERATLI ŞİİN ${ }^{3}$ \\ $\ddot{\mathrm{O} z}$
}

$\mathrm{Bu}$ araştırmanın amacı, bireylere sporda sürdürülebilir yaşamın kazandırlabilmesi ve gelecek nesillere aktarılması adına beden eğitimi öğretmenlerinin sporda sürdürülebilirliğe yeterliliği açısından belirlenmesidir. Araşıırmanın evrenini Kahramanmaraş İli merkezindeki ortaokul ve liselerdeki beden eğitimi öğretmenleri oluşturmaktadır. Araştırmanın örneklemini ise, 2019-2020 Eğitim-Öğretim yllında Kahramanmaraş ili merkezinde bulunan ortaokul ve liselerde görev yapan 232 beden eğitimi ögretmenleri oluşturmaktadır. Araştırmada veri toplama aracı olarak, katıllımcıların demografik özelliklerini belirlemeye yönelik değișkenler ve Koçak vd., (2013) tarafindan geliștirilen 35 maddelik 6 alt boyuttan oluşan "Sporda Sürdürülebilirlik Ölçeği (SSÖ)" kullanılmışır. Verilerin analizinde frekans ve yüzde hesaplanmaları yapılmış ve verilerin dağılımının belirlenmesi için skewness ve kurtosis değerleri incelenmiştir. Verilerin analizinde; $\mathrm{t}$ testi ve tek yönlü varyans analizi (ANOVA) kullanılmıștır $(\mathrm{p}<0.05)$. Araștırma sonucunda sporda sürdürülebilirlik boyutları bakış açılarında; cinsiyete göre farklılık bulunmuş erkek beden eğitimi öğretmenlerin algılamaları kadınlara göre ve takım sporuyla uğraşanların bireysel sporla uğraşanlara göre algılamaları yüksek bulunmuştur. Yaşları genç ve meslekte çalş̧ma yılı az olan öğretmenlerin ise sporda sürdürülebilirlik algılamaları düşük çıkmıştır. Sonuç olarak beden eğitimi öğretmenlerinin orta düzeyde sporda sürdürülebilirlilik algılaması içerisinde olduğu sonucuna ulaşıldı.

Anabtar Kelimeler: Beden Eğitimi, Spor, Sürdürülebilirlik, Öğretmen,

\section{Physical Education Teachers Perspective for Sustainability Success in Sports}

\begin{abstract}
The purpose of this research is to determine physical education teachers in terms of their adequacy in sports sustainability in order to provide individuals with a sustainable life in sports and to transfer them to future generations. The sample of the research consists of 232 physical education teachers working in secondary and high schools in the city center of Kahramanmaraş in the 2019-2020 academic year. 5-point Likert scaled "Sustainability in Sports Scale (SSS)" developed by Koçak et al. (2015) was used as data collection tool. Frequency and percentage calculations were made in the analysis of the data, and skewness and kurtosis values were examined to determine the distribution of the data. In statistical analysis; t-test was used for pairwise comparisons and ANOVA analysis was used for multiple comparisons. As a result of the research, in terms of sustainability dimensions in sports; The perceptions of male physical education teachers were found to be higher than females. The perceptions of teachers engaged in team sports were found to be higher than those engaged in individual sports. As a result of the research, it was determined that physical education teachers have a positive attitude towards sustainability in sports.
\end{abstract}

Key Words: Physical Education, Sports, Sustainability, Teacher

\section{Atıf İçin / Please Cite As:}

Şirin, T., Döşyllmaz, E. ve Eratlı Şirin, Y. (2022). Sporda sürdürülebilir başarı için beden eğitimi öğretmenleri bakış açıs1. Manas Sosyal Arastırmalar Dergisi, 11(1), 428-438.

Geliş Tarihi / Received Date: 10.06.2021

Kabul Tarihi / Accepted Date: 19.07.2021

\footnotetext{
1 Öğr. Gör. Dr. - Kahramanmaraş Üniversitesi Spor Bilimleri Fakültesi, tayfunksu@gmail.com

(iD) ORCID: 0000-0001-6305-0097

2 Dr. Öğr. Üyesi - Kahramanmaraş Üniversitesi, Spor Bilimleri Fakültesi, dosyilmaz@ksu.edu.tr

(iD) ORCID: 0000-0001-9973-3615

${ }^{3}$ Doç. Dr. - Çukurova Üniversitesi Spor Bilimleri Fakültesi, yelizsirin75@gmail.com

(i) ORCID:0000-0002-6143-1133
} 


\section{Giriş}

Sürdürülebilirlik kavramı özellikle dijitalleşen günümüzde tüm alanlarda en çok kullanılan terimlerden biridir. İşletmelerde, tarımsal alanlarda, ekonomik gelişimde, turizm alanlarında, sıkça kullanılan bu kavram toplumun sosyal, kültürel, bilimsel, doğal ve insan kaynakların tümünün özenli kullanımına dikkat çeken ve bunu koruma temelinde sosyal bir bakış algısı yaratan katılımcı bir süreç olarak tanımlanmaktadır (Gladwin vd., 1995, s. 877). Sürdürülebilirliliğin kullanıldığ1 bir diğer alanlardan biride sporda sürdürülebilirliktir. Sporun tüm alt sistemlerinin etkili ve verimli bir şekilde kullanılması spor alanında sürdürülebilir gelişmenin gerçekleşmesini sağlar. Spor da sürdürülebilirlik, sporun bütüncül bir yaklaşımla bütün sistemlerinin etkili ve verimli bir şekilde kullanılabilmesini gerektirir. Spor gelişiminin sürdürülebilirliğinden sorumlu kurumların yanı sıra en büyük sorumluk gelecek nesilleri eğitmekten sorumlu olan beden eğitimi öğretmenlerindedir. Çünkü spora katıllım, bireylerin psikolojik, fiziksel ve duygusal gelişimleri üzerinde önemli derecede olumlu sonuçlar ortaya koyduğu ve bunun sonucu olarak da bireylerin iletişim becerilerinin ve sosyal çevrelerine uyumun artmasıdır (Dinç, 2011, s. 1417). Bu nedenle gelecek kuşaklara daha yaşanabilir bir doğa bırakabilmek ve sporda sürdürülebilirliği sağlamak için bireylerin erken yaşlarda doğru bir şekilde eğitilmesi çok önemlidir ve en büyük görevde beden eğitimi öğretmenlerine düşmektedir.

$\mathrm{Bu}$ çalışma Beden Eğitimi öğretmenleri ile sporda sürdürülebilir gelişim arasında bağlantılar kurulmasına ve daha sürdürülebilir bir dünyaya katkıda bulunan öğrencilerin geliştirilmesi için farkındalık yaratmasına olanak tanıması düşünülmektedir.

\section{Kavramsal Çerçeve}

\section{Sürdürülebilirliğin Tanımı}

Sürdürülebilirlik kavram1; Dünya Çevre ve Kalkınma Komisyonu'nun (WCED)1987 yllında yayınladığ1 "Ortak Geleceğimiz" raporunda, ekosistemin ya da sürekliliği olan herhangi bir sistemin doğasını kaybetmeden, dejenere olmadan yeteri kadar kullanımı ve ana kaynakları çok fazla tüketmeden sürdürülebilmesi yetkinliği olarak tanımlanmaktadır (WCED,1987). İşletme stratejileri ve faaliyetlerinin kurumun ve paydaşların bugünkü ihtiyaçlarını karşılarken, gelecekte de ihtiyaç duyulacak doğal kaynakların ve insan refahının korunması ve artırılması amacıyla sürdürülebilirlik kavramı doğmuştur (Labuschagne, Brent, ve Van Erck, 2005, s. 380). Sürdürebilirlik son yllarda her alanda gündem oluşturan ve üzerinde çalısmalar yapılan bir kavramdır. Bu kavramın ana teması ve özelliği, insanların ve canlıların geleceğini içermesi ve hangi alan olursa olsun o alandaki kaynakların devamlılığın ve korunması ile ilgilidir (Beyhan ve Ünügür, 2005, s. 80). Temel dayanağı, teknolojik gelişmeler neticesinde ortaya çıkan çevre sorunlarını ve tahribatlarını engellemek ve doğal yaşamın korunmasına katkıda bulunmak olan sürdürülebilirlilik kavramı büyük önem göstermektedir (Balc1 ve Koçak, 2014, s. 50). Sürdürülebilirliğin en önemli dayanakları ise doğal kaynakların verimli kullanılması, atık azalımı, her türlü kaynağın geri dönüşümünün sağlanması, gelecek nesillerin ihtiyaçlarını karşılayabilecek ve doğal çevrenin korunmasıdır (Nemli, 2007). Sporun yaygınlaşıırılması ve öğretilmesi programlarının içerisindeki aktörlerin sporda sürdürülebilirlik hakkındaki görüşlerine ilişskin akademik literatürde çok az sistematik çalışma vardır. Bu çalışmalardan Lawson’a göre (2005, s. 140), spor yoluyla sosyal ve insani gelişmenin sürdürülebilirliğine odaklanırken, Dowda, Sallis, McKenzie, Rosengard ve Kohl (2005, s. 19) bir beden eğitimi programı aracıllğıyla sağlanan kaynakların sürekli kullanımını; Daha genel olarak Kirk (2004, s. 40), gençlerin spora katıllmının sürdürülebilirliğini; Lindsey (2008, s. 283) spor gelişiminde sürdürülebilirliği kavramsallaştırmak; McCullough, Pelcher ve Trendafilova, (2020, s. 13) Kuzey Amerika Spor Organizasyonları arasında Çevresel Sürdürülebilirlik; Mallen (2013, s. 120) spor “Tesislerinde Çevresel Sürdürülebilirlik Girişimleri’” gibi çalışmalar mevcuttur. Yapılan bu çalışmalar genelde sporda çevresel sürdürülebilirlilik üzerinedir. Bu katkılar, konseptin nasıl değerlendirilebileceği veya bütünüyle nasıl ele alınabileceği konusunda rehberlik sunmak yerine sürdürülebilirliğin belirli yönlerini inceleyerek sürdürülebilirliği dikkate almak için az sayıdaki spor geliştirme programları çalışmasını örneklemektedir. Son araştırmalar, beden eğitiminin sürdürülebilir aktif yaşama doğru yeniden yönlendirilmesine destek vermektedir. Penny (1999, s. 5) ve Penny ve Chandler (2000, s. 81) beden eğitiminin yeniden kavramsallaştırlmasının, aktivite temelli bir kavramdan uzakta ve toplumun karşı karşıya olduğu "kritik ikilemleri" ve "yeni gündemleri" yansıtan temaya dayalı bir müfredata doğru gerekli olduğunu öne sürmektedir. Çevresel kriz, açıça kritik bir ikilem ve sürdürülebilir kalkınma, oldukça önemli yeni bir gündem sunmaktadır. Lawson'ın (1995, s. 418) belirttiği gibi, beden eğitimi, spor bilimleri, sağlık, eğlence ve diğer yardımcı mesleklerdeki profesyoneller, küresel zorluklara 
yanıt verme ve kültürel olarak duyarlı ve değer adanmış uygulamalar yaratma sorumluluklarını paylaşmaktadır.

Sürdürülebilirliğin etkili olabilmesi için ilk aşamada, bireylerin sürdürülebilir açıdan yeterlilik taşıması gerekmektedir. Bu yeterliliği de sağlayacak olan davranış kazanımı, eğitimden geçmektedir(Çobanoğlu ve Türer, 2015).

Literatürde sürdürülebilirlilik ile ilgili Fien (1993) yaptığı araştırmada özellikle eğitimcilerin doğal ve sosyal çevrenin sürdürülebilirliğini artırmak için başka disiplinlerle ortak çalısmaları gerektiğini; Dowda vd. (2005, s. 13) ise araştırmalarında beden eğitimi programları ile kaynakların sürdürülebilir kullanımının önemini vurgulamışlardır. Aynı zamanda Dinç (2010, s. 662) beden eğitimi öğretmenliği programına devam eden öğrencilerin başarı hedef yönelimlerinin yüksek düzeyde olduğu sonucuna ulaşmıștır. $\mathrm{Bu}$ nedenle spor gelişiminde sürdürülebilirlik çalş̧ması için teorik bir temel sağlamak için diğer akademik alanlara yönelmek gerekmektedir. Bu alanlardan biride sporda sürdürülebilirliği önemli aktörlerinden olan sürdürülebilirliğin anlaşılmasını ve uygulanmasını sağlayan beden eğitimi ve spor eğitimi açısından değerlendirmek daha gerçekçi sonuçlar ortaya koyabilmektedir. Beden eğitimi dersi müfredat programlarında, ülkemizde ve birçok ülkede fiziksel aktivite ve sağlı̆ın önemi vurgulanmaktadır. Hardman (2002) tüm devletlerde eğitimde müfredatın en önemli kısmının beden eğitimi ve sporun olması gerektiğini tüm öğrenciler için zorunlu olmasını gerektiğini belirtmiştir.

\section{Sürdürülebilir Gelişme Bileşenleri ve Spor İlişkisi}

Lamberton (2005, s. 63) sürdürülebilirlik literatürünün genellikle ekolojik, ekonomik ve sosyal kaygıların bir kombinasyonuna oluştuğunu belirtmiştir. Bu boyutları kısaca şu şekilde tanımlamak mümkündür: Ekonomik sürdürülebilirlik, işletmelerin topluma yarar sağlayacak ürün ve hizmetleri üretirken, kar amacı güden kurumun fayda-maliyet analizi ile paydaşlar için uzun vadede değer yaratmayı amaçlamaktadır (Nemli, 2004, s. 81). Çevresel sürdürülebilirlik ise işletmelerin çevrenin doğasını bozmadan ya da en az düzeyde zarar verecek uygulamalarda bulunmasını ve çevrenin gelecek kuşakları düşünerek koruma altına alınmasını savunmaktadır (Gençoğlu ve Aytaç, 2016, s. 59). Sosyal (toplumsal) sürdürülebilirlik ise en önemli amacı Kalkınmayı ve ekonomik büyümeyi sağlamak, toplumların birbirleri ile örgütlenme ve etkileşim biçimlerini kapsayan, toplumdaki sosyal ayrıştırılma, cinsiyet eşitsizliği, fakirlik gibi olumsuz etkenleri yok etme, kısacası toplumun gelissmesi ve refahı adına gerekli olan kalkınma politikalarının uygulanması anlamına gelmektedir (Yeni, 2014, s. 196). Spor, toplum genelinde çevresel, sosyal ve ekonomik kalkınma için çevre bilincini, kapasite geliştirmeyi ve geniş kapsamlı eylemleri teşvik etmek için geniş firsatlar sunmaktadır. Sporda sürdürülebilirlik kavramının içeriğini, sporun uygulanmasını ve gelişmesini sağlayan spor tesislerinin, insanların huzuru ve yaşam kalitesinin arttırılması için kullanılması, işlevsel ve niteliksel özellikleri ile nesilden nesile aktarılacak organizasyonların oluşturulması ve bunların sistematik bir şekilde yönetilmesi olarak tanımlanmıştır (Koçak vd., 2013; Bossel, 1999). Spor adına sürdürülebilir bir gelişmenin uygulanması, sporun kapsamı içerisinde bulunan, çevresel, sosyal, kültürel, ekonomik vb. unsurların gelecek nesiller için korunması, aktarılması ve devamlılığının sağlanması, toplumu oluşturan bireylerin değerlerinin korunmasını, yaşadıkları çevre hakkında bilgi, beceri ve iletişimlerini geliştirdikleri bir süreci içine almaktadır (Özek vd. 1996). Sporda sürdürülebilirlik kavramı çok çeşitli boyutlarla ilişkilidir. Sürdürülebilirlik tanımlarından hareketle; sosyal, ekonomik ve çevresel boyutların, diğer tüm disiplinlerde olduğu gibi spor alanında da değişmez boyutlar olarak yer alması gerekmektedir. Ancak sporda ve beden eğitiminde sürdürülebilir gelişme, sürdürülebilirliği çeşitli alt boyutlara ayırmak ve bu şekilde tanımlamak ve uygulamak gerekmektedir. Çevresel bozulma sürdürülebilirliliğin ana konusu olarak kabul edilmekte ve pek çok disiplinin işbirliği yapmasının zorunlu olduğu bir sorundur. Sürdürülebilirliliğin spor alanında değerlendirilmesi açısından Koçak (2013) tarafindan yapılan çalışmada sporda sürdürülebilirlik örgütsel, bireysel, sosyal, ekonomik, çevresel ve katllım alt boyutları olan bir süreç olarak ortaya konulmuştur. Bu nedenle sporda sürdürülebilirlik, bu alt boyutları içeren ve gelecek kuşakların güvenilir bir şekilde spora katılımın sağlanmasını içeren bir süreç olarak değerlendirilmiştir. Sporda sürdürülebilirlik gelişiminde tanımlayıcı bir çerçeve oluşturmak için bireysel sürdürülebilirlik kavramına ihtiyaç vardır. Bireysel sürdürülebilirlik: Bireylerin çeşitli spor programlarına katılım yoluyla tutumlarında, yeteneklerinde ve/veya davranışlarında uzun vadeli meydana gelen değişiklikler olarak tanımlamıştır (Lindsey, 2008, s. 287). Çevresel sürdürülebilirlik, çevreyi bozan belirli organizasyonel faaliyetlerin çevresel etkisinden ve her bir etkiyi sınırlamaya ve / veya dengelemeye çalışan uygulamalardan oluşur (Mallen, Stevens, Adams ve McRoberts, 2010, s. 100). 90’lı yılların başında spor olayları ile çevre bilinci ve korunması gerekliliği olarak 90'lı yılların başında araştırlmaya başlanmıştır. Birleşmiş Milletler Çevre Programı (UNEP) ve Uluslararası Olimpiyat Komitesi1994 yllında olimpik ve paralimpik 
oyunlarının ortaya koyacağı çevresel etkileri engellemek ve azaltmak üzere beraber çalışmaya başlayarak, spor ve çevre bilincini birbirine bağlayan yapıyı oluşturmuşlardır (UNEP, 2005; Kellison ve Hong, 2015 , s. 260). Bu programa göre, spor tesislerinin inşa edilmesi, işletmede ve bakım aşamalarında çevre üzerindeki aşağıdaki etkileri bulunmaktadır (Mallen ve Chard, 2012, s. 235):

- Yakıt, metal vb. gibi yenilenemeyen kaynakların tüketimi, gürültü ve 1şık kirliliği.

- Su, ahşap, kağıt vb. doğal kaynakların tüketimi.

- Elektrik ve yakıt tüketerek sera gazlarının emisyonu.

- Tesislerin inşaatı ve izleyicilerin atık üretimi.

Spor örgütleri, çevresel sürdürülebilirlilik uygulamalarında taraftar farkındalığını ve onların katılımını arttırabilmek için atık geri dönüşümü ve enerji konusundaki hedeflerini web sitelerinde açıklamaktadır. Ayrıca, futbol tesislerinin temizlenmesi ve bakımı ile ilgili olarak, takımlar, biyolojik olarak parçalanabilen temizlik ürünleri ve güneş enerjili çöp sıkıştırıcıları kullanmanın yanı sıra atık yönetimi maliyetini ve enerji tüketimini düşürmek için hedefler belirlemektedir (Francis, Norris, ve Brinkmann, 2017, s. 398). Sporun tüm paydaşlarının organizasyon ve yarışmalara gidiş ve gelişten ortaya çıkan karbon emisyonları (Houghton, 2007, s. 327); hava kirliliğini ve trafik yoğunluğunu azalma amacı ile spor organizasyonlarına ve tesislerine toplu taşıma ile kolayca erişilebildiği yerlerde ulaşımla ilgili konulara da odaklanılmıştır (Francis vd., 2017, s. 394). Sosyal sürdürülebilirlik sağlık, eğitim gibi sosyal hizmetlerin yeterli ve adil olması, cinsiyet ayrımcılığının ortadan kaldırılması, fırsat eşitliği, sosyal adalet ve siyasi hesap verebilirliğin olduğu sistemi kapsayan bir yaklaşımdır (Harris, 2000). Toplumun her kesimi için sağlanan sağlık, eğitim, barınma koşullarının uygunluğu, adaletin sağlanması, uygun koşullarda iletişim ve ulaşım gibi hizmetlerin sosyal düzenin aksatılmasına meydan vermeden sürdürülmesi, sosyal sürdürülebilirliğin dayanak noktasını oluşturmaktadır (Akgül, 2010, s. 150).

\section{Yöntem}

\section{Araştırma Amac1}

$\mathrm{Bu}$ araştırmada sporda sürdürülebilirliliğin gelişimi için önemli bir etken olan beden eğitimi öğretmenlerinin sporda sürdürülebilirlik bakış açıları incelenmiştir. Bu amaç doğrultusunda aşağıdaki araştırmak sorularına cevap aranmıştır:

1. Beden eğitimi öğretmenlerinin sporda sürdürülebilirlik seviyeleri ne düzeydedir?

2. Sporda sürdürülebilirlik alt boyutları (Sosyal, Bireysel, Katılım, Ekonomik, Örgütsel ve Çevresel Boyut) ile beden eğitimi öğretmenlerinin demografik değişkenleri ile aralarında anlamlı bir farklilik var midir?

\section{Evren - Örneklem}

Araştırmanın örneklemini 2019-2020 eğitim-öğretim y1lında Kahramanmaraş ili merkezinde görev yapan ortaokul ve liselerde görev yapan 232 beden eğitimi öğretmeni oluşturmaktadır.

Araştırmaya katılan öğretmenlere ait demografik özellikleri incelendiğinde 58 (\%25) kadın, 174 (\%75) erkek; 67 (\%28,9) katılımcının 25-29 yaş aralığında; $46(19,8)$ öğretmenin 30-34 yaş aralığında; 43 öğretmenin 35-39 (\%18,5) yaş aralığ1; 76 öğretmenin ise 40 ve üstü yaş grubunda olduğu görülmüştür. Spor branşına göre incelendiğinde 148 öğretmenin takım sporu, 84 öğretmenin ise bireysel sporla ilgilendiği görüldü. Beden eğitimi öğretmenlerinin meslekte çalışma yılları incelendiğinde 51 (\%22) öğretmenin 1-3 y1l aras1, 71’inin (\%30.6) 4-7 y1l aras1, 53’ünün (\%22.8) 8-11 y1l aras1, 28’inin (\%12.1) 12-15 y1l aras1, 29(\%12.5) öğretmenin ise 16 y1l ve üzeri deneyime sahip olduğu görülmüştür.

\section{Veri Toplama Araçları}

Sporda Sürdürülebilirlik Ölçĕgi: Araştırmanın veri toplama aracı olarak, katılımcıların demografik özelliklerini belirlemeye yönelik değişkenler ve Koçak, Tuncel ve Tuncel, (2013) tarafindan geliştirilen "Sporda Sürdürülebilirlik Ölçeği (SSÖ)" kullanılmıştır. Bu ölçek 6 alt boyut ve 35 maddeden oluşmaktadır.

\section{Verilerin Analizi}

Araştırmada verilerine SPPS 22.0 paket programında frekans ve yüzde hesaplanmaları yapılmıştır. Verilerin dağılımın belirlemek için çarpıklık ve basıklık değerlerine bakılmış, değerlerin $-1,+1$ arasında 
olduğu belirlendiğinden dolayı verilerin normal dağıldığı sonucuna ulaşılmıştır (Büyüköztürk, Kılıç-Çakmak, Akgün, Karadeniz ve Demirel, 2017).

Araştırma verilerinin istatistiksel analizlerinde; ikili karşılaştırmalar için t testi, çoklu karşılaştırmalar için ise tek yönlü varyans analizi (ANOVA) kullanılmıştır ( $<$ 0.05). Koçak vd. (2013) tarafindan geliştirilen sürdürülebilirlik tutumları ölçeğin puanlaması; Olumlu tutum (3.34-5.00); Orta düzeyde tutum (1.67-3.33); Düşük tutum (0.00-1.66) olarak üç gruba ayrilmıştır.

Tablo 1. SSÖ Puanlar Ortalama ve Standart Sapma Değerleri

\begin{tabular}{|c|c|c|c|c|c|c|c|}
\hline Boyutlar & $\boldsymbol{N}$ & Min & $\operatorname{Max}$ & $A O$ & ss & Skewness & Kurtosis \\
\hline SS & 232 & 1.63 & 4.63 & 3.13 & .446 & -.032 & .036 \\
\hline BS & 232 & 1.75 & 5.00 & 3.55 & .519 & -.010 & .332 \\
\hline KS & 232 & 1.20 & 5.00 & 4.56 & .599 & -.226 & .907 \\
\hline ES & 232 & 1.67 & 4.83 & 3.09 & .522 & .900 & .270 \\
\hline ÖS & 232 & 1.00 & 5.00 & 3.72 & .598 & -.784 & .232 \\
\hline ÇS & 232 & 2.25 & 5.00 & 3.76 & .463 & -.648 & .492 \\
\hline SSÖ & 232 & 1.80 & 4.57 & 3.56 & .327 & -.723 & .543 \\
\hline
\end{tabular}

Sosyal Sürdürülebilirlike (SS) Bireysel Sürdürülebilirlike (BS) * Katıllm Sürdürülebilirlik (KS) * Ekonomik. Sürdürülebilirlik. (ES) *Örgütsel Sürdürülebilirlik (ÖS) * Cevresel Sürdürülebilirlik (CS) *Sporda Sürdürülebilirlik Ölçeği (SSÖ)

Tablo 1 incelendiğinde SSÖ’nün bütününe $(\chi=3.56 \pm$,32) ve alt boyutlarına bakıldığında en düşük tutum puanın ekonomik boyutunda $(\chi=3.09 \pm, 52)$, en yüksek tutum puanın ise katılım sürdürülebilirlik $(\chi=4,56 \pm, 59)$ olduğu görülmektedir. Bu değerler, öğretmenlerin SSÖ’nün bütününde ve bireysel, katılım, örgütsel ve çevresel sürdürülebilirlik alt boyutlarında olumlu tutum sergilediklerini, sosyal ve ekonomik sürdürülebilirlik alt boyutlarında ise orta düzeyde sürdürülebilirlik tutum sergilediklerini göstermektedir.

\section{Bulgular}

Tablo 2. Ögrretmenlerin Cinsiyetlerine Göre Sporda Sürdürülebilirlilik. Alt Boyutlar T-Testi Sonuclar

\begin{tabular}{|c|c|c|c|c|c|c|c|}
\hline Boyutlar & Grup & $n$ & $A O$ & $s d$ & $t$ & $d f$ & $\bar{p}$ \\
\hline \multirow{2}{*}{ SS } & Kadın & 58 & 2,27 & ,767 & $-2,116$ & 227 & 0,037 * \\
\hline & Erkek & 174 & 2,53 & 804 & & & \\
\hline \multirow{2}{*}{ BS } & Kadın & 58 & 3,46 & ,657 & 1,476 & 227 & 0,141 \\
\hline & Erkek & 174 & 3,58 & , 465 & & & \\
\hline \multirow{2}{*}{ KS } & Kadın & 58 & 4,46 & ,875 & 1,298 & 227 & 0,195 \\
\hline & Erkek & 174 & 4,58 & ,483 & & & \\
\hline \multirow{2}{*}{ ES } & Kadın & 58 & 3,00 & ,501 & 1,477 & 227 & 0,141 \\
\hline & Erkek & 174 & 3,12 &, 530 & & & \\
\hline \multirow{2}{*}{ ÖS } & Kadın & 58 & 3,68 & ,752 &,- 547 & 227 & 0,585 \\
\hline & Erkek & 174 & 3,73 &, 546 & & & \\
\hline \multirow{2}{*}{ ÇS } & Kadın & 58 & 3,65 & ,519 & 2,064 & 227 & $0,040 *$ \\
\hline & Erkek & 174 & 3,79 & ,441 & & & \\
\hline \multirow{2}{*}{ SSÖ } & Kadin & 58 & 3,50 & ,451 & 1,714 & 227 & 0,088 \\
\hline & Erkek & 174 & 3,58 & ,275 & & & \\
\hline
\end{tabular}

Sosyal Sürdürülebilirlik (SS) Bireysel Sürdürülebilirlik (BS) * Katılım Sürdürülebilirlik (KS) * Ekonomik Sürdürülebilirlik (ES) *Örgütsel Sürdürülebilirlik (ÖS) * Çevresel Sürdürülebilirlik (ÇS) *Sporda Sürdürülebilirlik Ölçeği (SSÖ)

Tablo 2'ye göre; öğretmenlerin sosyal sürdürülebilirlik $[\mathrm{t}(2,116)=0,037, \mathrm{p}<.05]$ ve çevresel sürdürülebilirlik alt boyutlarında $[\mathrm{t}(2,064)=0,040, \mathrm{p}<.05]$ cinsiyete göre anlamlı farklilik bulunmuştur. Bireysel sürdürülebilirlik boyutu $[\mathrm{t}(1,476)=0,141, \mathrm{p}>.05]$, spora katılımın desteklenmesi boyutu $[\mathrm{t}(1,298)=, 195, \quad \mathrm{p}>.05], \quad$ ekonomik sürdürülebilirlik boyutu $[\mathrm{t}(1,477)=0,141, \quad \mathrm{p}>.05], \quad$ örgütsel sürdürülebilirlik boyutu $[\mathrm{t}(-, 547)=0,585, \mathrm{p}>.05]$ ve sporda sürdürülebilirlik ölçeği toplam puanlarında $[\mathrm{t}(1,714)=0,088, \mathrm{p}>.05]$ olarak anlamlı farklılık bulunmamıştır. 
Tablo 3. Öğretmenlerin Spor Branşlarna göre Sporda Sürdürülebilirlilik. Alt Boyutlar T-Testi Sonuçlar

\begin{tabular}{|c|c|c|c|c|c|c|c|}
\hline & Gruplar & $n$ & $A O$ & $S d$ & $\bar{t}$ & $d f$ & $p$ \\
\hline \multirow{2}{*}{ SS } & Takım Sporlar1 & 148 & 2,75 & ,832 & 6,987 & 230 & $0,000 *$ \\
\hline & Bireysel Spor & 84 & 2,02 & 602 & & & \\
\hline \multirow{2}{*}{ BS } & Takım Sporları & 148 & 3,53 & ,515 &,- 761 & 230 & 0,451 \\
\hline & Bireysel Spor & 84 & 3,58 &, 527 & & & \\
\hline \multirow{2}{*}{$\mathrm{KS}$} & Takım Sporları & 148 & 4,54 & 608 &,- 679 & 230 & 0,498 \\
\hline & Bireysel Spor & 84 & 4,59 &, 586 & & & \\
\hline \multirow{2}{*}{ ES } & Takım Sporları & 148 & 3,07 & ,492 &,- 582 & 230 & 0,561 \\
\hline & Bireysel Spor & 84 & 3,11 & 574 & & & \\
\hline \multirow{2}{*}{ ÖS } & Takım Sporları & 148 & 3,74 &, 534 & ,717 & 230 & 0,474 \\
\hline & Bireysel Spor & 84 & 3,68 & 699 & & & \\
\hline \multirow{2}{*}{ ÇS } & Takım Sporları & 148 & 3,78 & 473 & 1,021 & 230 & 0,308 \\
\hline & Bireysel Spor & 84 & 3,72 & ,444 & & & \\
\hline \multirow{2}{*}{ SSÖ } & Takım Sporları & 148 & 3,55 & ,329 &,- 522 & 230 & 0,602 \\
\hline & Bireysel Spor & 84 & 3,58 & 327 & & & \\
\hline
\end{tabular}

Sosyal Sürdürülebilirlik (SS) Bireysel Sürdürülebilirlik (BS) * Katılım Sürdürülebilirlik (KS) * Ekonomik Sürdürülebilirlik (ES)

*Örgütsel Sürdürülebilirlik (ÖS) * Çevresel Sürdürülebilirlik (ÇS)*Sporda Sürdürülebilirlik Ölçeği (SSÖ)

Tablo 3 incelendiğinde araştırmaya katılan öğretmenlerin sporda sürdürülebilirlik tutumlarının spor branş1 değişkenine göre, sosyal sürdürülebilirlik alt boyutunda anlamlı farklillğa rastlanmıştır $[\mathrm{t}(6,987)=0,000, \mathrm{p}<.05]$. Sonuçlara göre takım sporu ile uğraşan öğretmenlerin ortalamaları bireysel sporla uğraşanlardan sosyal sürdürülebilirlik yönelimleri daha yüksek çıkmıştır. Bireysel sürdürülebilirlik $[\mathrm{t}(-, 761)=0,451, \mathrm{p}>.05]$, spora Katılım sürdürülebilirlik[t(-,679)=0,498, $\mathrm{p}>.05]$, ekonomik sürdürülebilirlik $[\mathrm{t}(-, 582)=0,561, \quad \mathrm{p}>.05]$, örgütsel sürdürülebilirlik $[\mathrm{t}(.717)=0,474, \quad \mathrm{p}>.05], \quad$ çevresel sürdürülebilirlik $\left[\mathrm{t}(1,021)=0,308, \mathrm{p}^{>} .05\right]$ alt boyutlarında ise anlamlı farklılığa rastlanmamıştır. Sporda sürdürülebilirlik ölçeği toplamında da spor branşı değisşkenine göre anlamlı farklılık görülmemiştir [t($, 522)=0,602, \mathrm{p}>.05]$.

Tablo 4. Ögretmenlerin Yas Gruplarna Göre Sporda Sürdürülebilirlilik. Alt Boyutlan ANOV A Testi Sonuclar

\begin{tabular}{|c|c|c|c|c|c|c|c|c|}
\hline \multicolumn{2}{|c|}{ Değişken } & \multirow{2}{*}{$\frac{S S}{X \pm S}$} & \multirow{2}{*}{$\frac{B S}{X \pm S}$} & \multirow{2}{*}{$\frac{K S}{X \pm S}$} & \multirow{2}{*}{$\frac{E S}{X \pm S}$} & \multirow{2}{*}{$\frac{\ddot{O} S}{X \pm S}$} & \multirow{2}{*}{$\frac{C S S}{X \pm S}$} & \multirow{2}{*}{$\frac{S S O ̈}{X \pm S}$} \\
\hline Yaş & $\boldsymbol{N}$ & & & & & & & \\
\hline 25-29 yaş & 67 & $3,15 \pm, 47$ & $3,47 \pm, 58$ & $4,50 \pm, 79$ & $3,10 \pm, 62$ & $3,52 \pm, 66$ & $3,72 \pm, 59$ & $3,52 \pm, 41$ \\
\hline $30-34$ yaş & 46 & $3,11 \pm, 34$ & $3,59 \pm, 44$ & $4,58 \pm, 47$ & $3,09 \pm, 46$ & $3,80 \pm, 54$ & $3,76 \pm, 47$ & $3,58 \pm, 27$ \\
\hline $35-39$ yaş & 43 & $3,19 \pm, 35$ & $3,60 \pm, 52$ & $4,66 \pm, 55$ & $3,19 \pm, 45$ & $3,92 \pm, 51$ & $3,81 \pm, 35$ & $3,65 \pm, 22$ \\
\hline $40-45$ yaş & 36 & $3,19 \pm, 50$ & $3,49 \pm, 52$ & $4,53 \pm, 46$ & $3,00 \pm, 40$ & $3,70 \pm 47$ & $3,76 \pm, 34$ & $3,54 \pm, 30$ \\
\hline $46-50$ yaş & 30 & $2,97 \pm, 49$ & $3,62 \pm, 50$ & 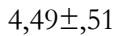 & $3,02 \pm, 62$ & $3,67 \pm, 70$ & $3,82 \pm, 40$ & $3,52 \pm, 33$ \\
\hline 51 > yaş & 10 & $3,17 \pm, 61$ & $3,63 \pm, 46$ & $4,66 \pm, 47$ & $2,98 \pm, 37$ & $3,95 \pm 43$ & $3,55 \pm, 40$ & $3,59 \pm 29$ \\
\hline $\mathrm{F}=$ & & 1,138 &, 672 &, 537 &, 719 & 2,991 &, 750 & 991 \\
\hline $\mathrm{P}=$ & & 0,341 & 0,645 & 0,748 & 0,610 & $0,012 *$ & 0,587 & 0,424 \\
\hline Post hoc: & & & & & & $1<2,3,6$ & & \\
\hline
\end{tabular}

Sosyal Sürdürülebilirlik (SS) Bireysel Sürdürülebilirlik (BS)* Katılım Sürdürülebilirlik (KS) * Ekonomik Sürdürülebilirlik (ES) *Örgütsel Sürdürülebilirlik (ÖS) * Çevresel Sürdürülebilirlik (ÇS) *Sporda Sürdürülebilirlik Ölçeği (SSÖ)

Tablo 4 incelendiğinde araştırmaya katılan öğretmenlerin sporda sürdürülebilirlik tutumlarının yaş değişkenine göre örgütsel sürdürülebilirlik alt boyutunda anlamlı farklılı̆̆a rastlanmışır $(\mathrm{p}<.05)$. Sonuçlar incelendiğinde yaşı 25-29 yaş arası olan öğretmenlerin ortalamaları daha yüksek yaş grubundaki öğretmenlere göre düşük çıkmıştır. Sosyal sürdürülebilirlik, bireysel sürdürülebilirlik, spora katılımın desteklenmesi, ekonomik sürdürülebilirlik, çevresel sürdürülebilirlik alt boyutlarında ise anlamlı farklıllğa rastlanmamıştır ( $\mathrm{p}>.05)$. 
Tablo 5. Öğretmenlerin Öğretmenlikde Çalısma Yılına Göre Sporda Sürdürülebilirlilik Alt Boyutlar ANOV A Testi Sonuclar

\begin{tabular}{|c|c|c|c|c|c|c|c|c|}
\hline Değişken & & SS & BS & KS & ES & ÖS & ES & SSÖ \\
\hline Çalısma Yil & $N$ & $A O \pm S$ & $A O \pm S$ & $A O \pm S$ & $A O \pm S$ & $A O \pm S$ & $A O \pm S$ & $A O \pm S$ \\
\hline $1-3 \mathrm{yll}$ & 51 & $3,05 \pm, 37$ & $3,38 \pm, 49$ & $4,65 \pm, 65$ & $3,09 \pm, 50$ & $3,62 \pm 57$ & $3,84 \pm 44$ & $3,52 \pm 30$ \\
\hline 4-7 y1l & 71 & $3,19 \pm, 46$ & $3,63 \pm, 53$ & $4,52 \pm, 59$ & $3,03 \pm, 48$ & $3,70 \pm, 60$ & $3,71 \pm, 40$ & $3,57 \pm, 32$ \\
\hline 8-11 yil & 53 & $3,13 \pm, 47$ & $3,46 \pm, 48$ & $4,55 \pm, 58$ & $3,18 \pm, 54$ & $3,75 \pm 49$ & $3,83 \pm, 48$ & 3,57士,31 \\
\hline 12-15yll & 28 & $3,14 \pm, 42$ & $3,66 \pm, 54$ & $4,56 \pm, 69$ & $3,07 \pm, 51$ & $3,99 \pm, 64$ & $3,73 \pm, 52$ & $3,61 \pm 39$ \\
\hline $16>$ & 29 & $3,14 \pm, 49$ & 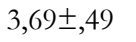 & $4,51 \pm, 44$ & $3,06 \pm, 62$ & $3,60 \pm, 68$ & $3,62 \pm, 50$ & $3,55 \pm, 32$ \\
\hline $\mathrm{F}=$ & & ,703 & 3,008 & ,396 & ,648 & 2,154 & 1,699 & ,420 \\
\hline $\mathrm{P}=$ & & 0,590 & $0,019 *$ & 0,811 & 0,629 & 0,075 & 0,151 & 0,794 \\
\hline post hoc: & & & $1<2,4,5$ & & & & & \\
\hline
\end{tabular}

Sosyal Sürdürülebilirlik (SS) Bireysel Sürdürülebilirlik (BS) * Katılım Sürdürülebilirlik (KS) * Ekonomik Sürdürülebilirlik (ES)

*Örgütsel Sürdürülebilirlik (ÖS) * Çevresel Sürdürülebilirlik (ÇS) *Sporda Sürdürülebilirlik Ölçeği (SSÖ)

Tablo 5 incelendiğinde araştırmaya katılan öğretmenlerin sporda sürdürülebilirlik tutumlarının çalışma yllı değişkenine göre, bireysel sürdürülebilirlik alt boyutunda anlamlı farklılığa rastlanmıştır $(\mathrm{p}<.05)$. Post hoc testi sonuçlarına göre çalışma deneyimi düşük olan öğretmenlerin bireysel sürdürülebilirlik algilamaları, deneyimi yüksek olan öğretmenlere göre düşük çıkmıştır. Sosyal sürdürülebilirlik, spora katılımın desteklenmesi, ekonomik sürdürülebilirlik, örgütsel sürdürülebilirlik, çevresel sürdürülebilirlik alt boyutlarında ise anlamlı farklılığa rastlanmamıştır ( $>$ >.05).

\section{Tartışma ve Sonuç}

$\mathrm{Bu}$ araştırma sürdürülebilir kalkınmanın kendisi tartışmalı bir konu olduğundan dolayı sporda sürdürülebilirliğin beden eğitimi öğretmenleri üzerindeki etkilerinin bir araştırma konusu olduğu kabul edilerek yapılmıştır. Beden eğitimi ders müfredatlarında öğrencilerin kişisel ve sosyal gelişimleri aynı madalyonun iki yüzü olarak ele alındığ1 görülmektedir. Bu nedenle sporda sürdürülebilirliğin gelişimi ve genç nesillere aktarımı bakımından öğretmenlerin bakış açları önem arz etmektedir.

$\mathrm{Bu}$ araştırmada beden eğitimi öğretmenlerinin sporda sürdürülebilirliğe karşı bakış açıları bazı demografik faktörlerle (cinsiyet, yaş, spor branşı, mesleki deneyim) ilişkisi incelenmiştir. Araştırmanın bulguları gözden geçirildiğinde; beden eğitimi öğretmenlerinin sporda sürdürülebilirliğe karşı olumlu tutum sergiledikleri bulundu.

Araştırmanın sonucunda erkek öğretmenlerin hak ve özgürlüklerin korunmasını, sosyal adalet ve siyasi hesap verebilirliğin olduğu sistemi kapsayan sosyal sürdürülebilirliğin önemine yönelik daha duyarlı oldukları söylenebilir. Aynı zamanda çevresel sürdürülebilirlik boyutunu kapsayan kaynak tüketimi en aza indirme, atıkların yeniden kullanılarak geri dönüşümlerinin sağlanması, yenilenebilir ve kirlilik oluşturmayan enerji kaynaklarının üretilmesi açısından gelecek nesillere daha yaşanabilir ve spor yapılabilir bir çevre bırakma açısından önemli boyut olduğunu düşündükleri söylenebilir. Literatürdeki çalısmalardan, Demirel (2009); Deniş ve Genç (2007, s. 24); Fransson ve Garling (1999, s. 400) yaptıkları çalışmalarında kadınların çevresel tutuma yönelik duyarlılıklarının erkeklere göre daha yüksek olduğunu saptamışlardır. Araştırmanın diğer bir sonucu olarak, sporun yaygınlaştırılmasında sorumlu kurum ve kuruluşların üzerine düşen görevleri yerine getirmesi, spor politika ve uygulamaları koşullardaki değişikliklerin spor açısından kapsamlı bir biçimde ele alınarak uygun düzenlemelerin yapılması (Koçak, 2013) olarak tanımlanan Sporda örgütsel sürdürülebilirlik boyutuna yaşı daha büyük olan öğretmenlerin genç olanlara göre algılamaları yüksek bulunmuştur. Sonuçla öğretmenlerin deneyimlerine ve yaşanmışlıklarının genç öğretmenlere göre fazla olmasından belirlenen spor politikalarının uygulanabilirliğinde, kitle iletişim araçlarının önemi, etik sorunların çözülmesi, spor organizasyonlarının önemi, uluslararası arenada sportif başarı kazanma gibi alt temaları içerdiği için sporda sürdürülebilirliğin sağlanması açısından sporun sosyal boyutunun önemine daha fazla önem gösterdikleri söylenebilir. Yücel, (2018); Koçak'ın (2013, s. 125) yaptıkları araştırmada öğrencilerin yaş değişkenine göre sporda sürdürülebilirliğe ilişkin tutumları arasında anlamlı bir farklıllğa rastlanmamıştır.

Öğretmenlerin Sporda sürdürülebilirlik tutumlarının takım sporu ile uğraşan öğretmenlerin sosyal sürdürülebilirlik alt boyutunda bireysel sporla uğraşan katılımcllara göre yüksek bulunmuştur. Sporda sosyal sürdürülebilirlik; spor yapmada firsat eşitliğini, sportif etkinliklere katılım hakkını, sosyal yaşamı iyileştirmeyi, spor yoluyla toplumsal duyarlılığı artırmayı, spor kültürünün oluşturulmasını, sporu insan ihtiyacı olarak algılanmasını içermesinden dolayı öğretmenlerin sosyal sürdürülebilirliğe ilişkin tutumlarının 
yüksek çıkmasını etkilemiş olabileceği düşünülmektedir. Koçak'ın (2013, s. 126) yaptığı araştırmada ögrencilerin branşları ile sporda sürdürülebilirliğe ilişkin tutumları arasında farklılık bulunmamıştır.

Araştırmanın diğer bir sonucu olarak da sporda sürdürülebilirlik tutumlarının mesleki deneyimi 16 yıl ve üzeri olan öğretmenlerin bireysel sürdürülebilirlik tutumlarının yüksek olduğu bulunmuştur. Mesleki deneyimi yüksek olan öğretmenlerin, öğrencilerde becerilerin geliştirilmesi, sosyalleşme, sağlı̆̆ı önemi ve korunması, kişisel gelişim, kaliteli yaşam farkındalığının artması gibi temalardan oluşan bireysel sürdürülebilirliği (Koçak, 2015, s. 228) önemsedikleri söylenebilir. Bu alt temaları mesleki deneyimleri sayesinde daha çok tecrübe ettikleri, çocuklarla ve gençlerle beden eğitimi ve spor alanında birebir görev yapan bireyler olmalarından dolayı bireysel sürdürülebilirliliğin dinamiklerinin önemini vurguladıkları söylenebilir. Bireylerin spora katılımı ve teşviki olarak tanımlanan bireysel sürdürülebilirlik, tutum, yetenek ve/veya davranışlarında uzun dönemli olumlu değişiklikler geliştirme olarak tanımlanmıştır (Lindsey, 2008, s. 281). Bu noktada beden eğitimi öğretmenlerine çok büyük sorumluluk almaktadır. Çünkü beden eğitimi öğretmeni sporun ne olduğunu branşları sağlık için sporun faydalarını belki de ögrencilere ilk tanıtan ve anlatan kişidir. Atılgan (2018, s. 12) araştırmasında beden eğitimi öğretmenlerinin özgüveni yüksek kişiler olduğunu belirtmiştir. Okullarda en çok rol model olarak görünen branş öğretmeni beden eğitimi öğretmenleridir. Bu nedenle öğrencilere bireysel sürdürülebilirliğin yanı sıra eğitim, sağlık gibi toplumsal hizmetlerin yeterliliğ̈i, firsat eșitliği, sosyal adalet, cinsiyet eşitliği gibi temaları (Koçak, 2015, s. 230) içeren Sosyal sürdürülebilirliğin de önemini anlatma beden eğitimi öğretmenlerinin en birincil görevleridir. Spor Katılımından elde edilen ekonomi değerinin yanı sıra, bireylerin fiziksel, zihinsel, sosyal ve psikolojik refahını artırmaya yönelik doğal değerlere sahiptir (Hamafyelto, 2006, s. 258). Bu açıklamaya göre, sporun birincil amacının bireysel sürdürülebilirlik olduğu görülmektedir

$\mathrm{Bu}$ açıklamalara dayanarak daha sürdürülebilir bir dünya yaratmak için okulların sorgulayan, sorumlu ve araştıran insanlar üretmesi gerekmektedir. Bilgi, alg1 ve değer kazanımı da bireyin eğitimi yoluyla sağlanabilir. Bu noktada en çok bireye öğretmenler aracıllğıyla ulaşılabilir. Öyleyse öğretmen ve öğretmen adaylarının sürdürülebilir kalkınma ve gelecekte yaşanabilir bir dünya yaratma konusunda bilgi, algı ve değerler bazında iyi donatılmış olmaları şarttır. Her yaştan bireyin sürdürülebilir bir gelecek için sorumluluk üstlenmesini sağlamak için onlara model olacak öğretmen ve öğretmen adaylarının sürdürülebilir bir dünya ve yaşam biçiminin farkında olması sağlanmalıdır (Demirbaş, 2015). Gençlerin güçlü bir ahlaki alg1 geliştirmelerine yardımcı olacak türden deneyimler sağlamalılar, böylece çevrelerindeki dünyada olup bitenlere eleştirel bir gözle bakacaklar ve kanaatlerine göre hareket etme gücüne, sosyal ve çevresel sorunlara çözüm bulma becerilerini ve analitik yeteneklerini geliştirebilirler. Yenileme yalnızca tabandan gelebilir ve eğitimin zorluğu, küreselleşmiş bir sistem içinde güçlü yerel demokrasiler yaratmaya yardımc1 olmak için bu sürece kilitlenmektir. Bu sürecin uygulayıcılarından biri olan beden eğitimi öğretmenlerinin sorumlulukları sadece beden eğitiminde çeşitli aktiviteleri öğrencilerine aktarmak değil daha da önemlisi aynı aktiviteleri anlamanın ve değer vermenin çevresel, sosyal, bireysel sonuçlarına ilişkin farkındalıklarını arttırmaktadır.

Sonuç olarak sporda sürdürülebilirliliğin toplum içerisinde gelişmesinin ilk uygulayıcıları olan beden eğitimi öğretmenlerinin farkındalık yaratmada öncü oldukları gelecek nesillerin duyarllıklarının artması açısından önem arz etmektedir. Beden eğitimi ders programları içerisinde kaynakların sürdürülebilir kullanımına yönelik ders ve konuların eklenmesi öğretmenlerin sürdürülebilirliğe yönelik farkındalık, tutum ve davranıs düzeylerinin gelișmesine ve öğrencilerine bu konuda daha geniş bir perspektif den bakmalarına ve duyarllıklarının artmasına neden olacaktır. Bu nedenle sporda sürdürülebilirliğin önündeki engelleri kaldırmada eğitimin en önemli faktörlerden biri olduğu söylenebilir.

\section{Öneriler}

Gelecekteki araştırmalar, sporun çeşitli paydaş gruplarının spor organizasyonlarının sporda sürdürülebilirliğe yönelik beklentilerine odaklanmalıdır. Aynı zamanda beden eğitimi öğretmenleri için düzenlenen hizmet içi eğitim seminerlerine sürdürülebilir kalkınma ile ilgili ve özellikle sporda sürdürülebilirliğe yönelik eğitimler dâhil edilmelidir. Her eğitim kademesinde gerçekleştirilen projeler gibi sporda sürdürülebilir gelişme ile ilgili konular ele alınarak projeler geliştirilip özellikle eğitimin her kademesindeki öğrencilerin katılımı sağlanarak sporda sürdürülebilirlilik farkındalığının arttırılması önerilebilir. 


\section{Etik Beyan}

"Sporda Sürdürülebilir Başar İçin Beden Eğitimi Öğretmenleri Bakııs Açısı” başlıklı çalışmanın yazım sürecinde bilimsel kurallara, etik ve alınt kurallarına uyulmuş; toplanan veriler üzerinde herhangi bir tahrifat yapılmamış ve bu çalışma herhangi başka bir akademik yayın ortamına değerlendirme için gönderilmemiştir. Bu araştırma, Çukurova Üniversitesi Tip Fakültesi Girişimsel Olmayan Klinik araştırmalar Etik Kurulu'nun 22.05.2021 tarih ve Karar NO:60 sayllı izni ile uygulanmıştır.

\section{Kaynakça}

Akgül U. (2010). Sürdürülebilir kalkınma: Uygulamalı antropolojinin eylem alanı. Ankara Üniversitesi Dil ve Tarih Coğrafya Fakültesi Antropoloji Dergisi, 24, 133- 164.

Atılgan D. (2018). Beden eğitimi öğretmenleri ve antrenörlerin özgüven düzeyleri ile karar verme stilleri arasındaki ilişkinin incelenmesi. Atatürk Üniversitesi Beden Eüitimi ve Spor Bilimleri Dergisi, 20(4), 8-22

Balcı, V. ve Koçak, F. (2014). Spor ve rekreasyon alanlarının tasarımında ve kullanımında çevresel sürdürülebilirlik. Spor ve Performans Arastirmalar Dergisi, 5(2), 46-58.

Beyhan Ş. G. ve Ünügür S. M. (2005). Çağdaş gereksinmeler bağlamında sürdürülebilir turizm ve kimlik modeli. İTÜ Dergisi, 4(2), 79-87.

Bossel, H. (1999). Indicators for sustainable development: Theory, method, applications: a report to the balaton group. winnipeg: International Institute for Sustainable Development (IISD), Canada.

Büyüköztürk, Ş., Kılıç-Çakmak, E., Akgün Ö. A., Karadeniz Ş. ve Demirel F. (2017). Eğitimde bilimsel araştırma yöntemleri. Ankara: Pegem Akademi.

Çobanoğlu, O. ve Türer, B. (2015). Fen bilgisi ve sosyal bilgiler öğretmenlerinin sürdürülebilir kalkınma farkındalıklarının belirlenmesi. Uluslararası Türk Ë̆itim Bilimleri Dergisi, 2015(5), 235-247.

Demirel, M. (2009). Rekreasyonel etkinliklere katılım ve çevresel duyarllhk (Doktora Tezi). Gazi Üniversitesi, Eğitim Bilimleri Enstitüsü, Ankara.

Demirbaş, Ö. Ç. (2015). Öğretmen adaylarının sürdürülebilir kalkınma farkındalık düzeyleri. Marmara Coğrafya Dergisi, $31,300-316$

Deniş, H. ve Genç, H. (2007). Çevre bilimi dersi alan ve almayan sınıf öğretmenliği öğrencilerinin çevreye ilișkin tutumları ve çevre bilimi dersindeki başarılarının karşılaştırılması, Mebmet Akif Ersoy Üniversitesi, Eğitim Fakültesi Dergisi, 8(13), 20-26.

Dowda, M., James, F, Sallis, J. F., McKenzie, T. L., Rosengard, P. ve Kohl, H. W. (2005). Evaluating the sustainability of SPARK physical education: A case study of translating research into practice. Res Q Exerc Sport, 76(1), 9-19. doi: 10.1080/02701367.2005.10599257.

Dinç, Z. F. (2010). Relationship between achievement goal orientation and physical seşf-perception among students attending physical education teaching. World Applied Sciences Journal, 11(6), 662-668.

Dinc, Z. F. (2011). Social Self-efficacy of adolescents who participate in individual and team sports. Soczal Behavior and Personality, 39(10), 1417-1423.

Fien, J. (1993). Education for the environment: Critical curriculum theorizing and environmental education. Geelong: Deakin University Press.

Francis, T., Norris, J. ve Brinkmann, R. (2017). Sustainability initiatives in professional soccer. Soccer Soc, 18, $396-406$.

Fransson, N. ve Garling, T. (1999). Environmental concern: Conceptual definitions measurement methods and research finding, Journal of Environmental Psychology, 19, 369382.

Gençoğlu, Ü. ve Aytaç, A. (2016). Kurumsal sürdürülebilirlik açısından entegre raporlamanın önemi ve BIST uygulamalar1. Mubasebe ve Finansman Dergisi, 72, 51-66.

Gladwin, T., Kennely, J. ve Krause, S. T. (1995). Shifting paradigms for sustainable development: Implications for management theory and research, Academy of Management Review, 20(4),874-907.

Hamafyelto, S. S. (2006). Goal orientation and sports participation motives of secondary school students in Borno State. ICHPER-SD. African Region, 1(1), 56-60.

Hardman K. (2002). Council of Europe Committee for the development of sport (CDDS), Report on School Physical Education in Europe. MSL-IM, 16, 9, Council of Europe, Strasbourg, 2002.

Harris, M. J. (2000). Basic principles of sustainable development. Global Development and Environment Institute Working Paper. USA: Tufts University.

Houghton, R. A. (2007). Balancing the global carbon budget, Annual Review of Earth and Planetary Sciences, 35, $313-347$. DOI: 10.1146/annurev.earth.35.031306.140057

Hoye, R., Nicholson, M. ve Haulihan, B. (2015). Spor ve politika meseleleri ve analiz̧i (Çev: C. Tinaz, M. Bakır (Ed.) (1. Basim). İstanbul: Beta.

Kellison, T. B. ve Hong, S. (2015). The adoption and diffusion of pro-environmental stadium design, European Sport Management Quarterly, 15(2), 249-269.

Kirk, D. (2004). Sport and early learning experiences. in driving up participation: The Challenge for Sport. London: Sport England. p. 69-77.

Koçak F., Tuncel, F. ve Tuncel, S. (2013). Sporda sürdürülebilirliğin boyutlarının belirlenmesi. Ankara Üniversitesi Spor Bilimleri Fakültesi Dergisi, 11(2), 113-129. 
Koçak, F., Tuncel, S. ve Tuncel, F. (2015). Sporda sürdürülebilirlik ölçeği’nin geçerlik ve güvenirlik çalışması: Türk üniversite öğrencileri. Niğde Üniversitesi Beden Ë̆itimi ve Spor Bilimleri Dergisi, 9(2), 220-235.

Koçak, F. (2013). Sporda sürdürülebilirliğin değerlendirilmesi (Doktora Tezi). Ankara Üniversitesi Sağlık Bilimleri Enstitüsü, Ankara.

Labuschagne, C., Brent, A.C. ve Van Erck, R. P. G. (2005). Assessing the sustainability performances of industries. Journal of Cleaner Production, 13, 373-385.

Lamberton, G. (2005). Sustainable sufficiency: An internally consistent version of sustainability. Sustainable Development, 13(1), 53-68.

Lawson, H. A (2005). Empowering people, facilitating community development, and contributing to sustainable development: the social work of sport, exercise, and physical education programs sport, Education and Society, 10(1), 135-160.

Lawson, H. A. (1995). International changes and challenges: Their import for new models for practice. Quest, 47, 411-426.

Lindsey, I. (2008). Conceptualizing sustainability in sports development. Leisure Studies, 27(3), 279-294.

Mallen, C., Chard, C. ve Sime., L. (2013). Web communications of environmental sustainability initiatives at sport facilities hosting major league soccer. Journal of Management and Sustainability, 3(3), 115-130.

Mallen, C., Stevens, J., Adams, L. ve McRoberts, S. (2010). An assessment of the environmental performance of an international multi-sport event: Understanding the organizational barriers to event sustainability. European Sport Management Quarterly, 10(1), 97-122.

Mallen, C. ve Chard C. (2012). What could be in Canadian sport facility environmental sustainability. Sport Management Review, 15, 230-243.

McCullough, B. P., Pelcher, J. ve Trendafilova, S. (2020). An exploratory analysis of the environmental sustainability performance signaling communications among North American sport organizations. Sustainability, 12(5), 2-17.

Nemli E. (2004). Sürdürülebilir kalkınma: Şirketlerin çevresel ve sosyal yaklaşımlarm. İstanbul: Filiz Kitabevi.

Nemli, E. (2007). Sürdürülebilir gelişme: Ekonomi ile çevre arasındaki denge. Sunum, İstanbul, Kalder-Çevre Uzmanlik Grubu, http://www.kalder.org.tr.

Özek, V., Sirel, A. ve Akansel, S. (1996). Turiz̧m-araş mı, amaş mı? Dünya şehircilik kolokyumu. Alanya, Mimar Sinan Üniversitesi Matbaas1, İstanbul, 143-15.

Penny, D. (1999). Physical education: In changing times is it time for a change? British Journal of Physical Education, 30(2), 4-6.

Penny, D. ve Chandler. T. (2000). Physical education: What future(s)? Sport, Education and Societ', 5(1), 71-87.

Preuss, H. (2013). The contribution of the FIFA World Cup and the Olympic Games to green economy, Sustainability, 5,3581-3600, doi:10.3390/su5083581.

WCED. (1987). World commission on environment and development, our common future: The brundtl and report. Oxford: Oxford University Press.

Yeni, O. (2014). Sürdürülebilirlik ve sürdürülebilir kalkınma: Bir yazın taraması. Gaz̨i Üniversitesi İktisadi ve İdari Bilimler Fakültesi Dergisi, 16 (3), 181-208.

Yücel, A. S., Eskiyecek, C. B., Çiftçi, İ., Tan, Ç., Savucu, Y. ve Türkmen, A. (2018). Lisans öğrencilerinin sporda sürdürülebilirliğe ilişkin görüşlerinin değerlendirilmesi (Fırat Üniversitesi Örneği), Mukaddime, 9(2), 261-292.

\section{EXTENDED ABSTRACT}

One of the most used concepts in all disciplines today is the concept of sustainability. The concept of sustainability is a frequently used concept in agriculture, tourism, architecture, businesses and economy. One of the other areas where sustainability is used is sustainability in sports. A sustainable development in the field of sports occurs when all subsystems of the sport can be used effectively and efficiently. Sustainability in sports requires the effective and efficient use of all systems of sports with a holistic approach. Besides the institutions responsible for the sustainability of sports development, the biggest responsibility lies with the physical education teachers who are responsible for educating future generations. Because it is very important to train individuals correctly at an early age in order to leave a more livable nature to future generations and to ensure sustainability in sports. This research has been conducted with the acceptance that the effects of sustainability in sports on physical education teachers are a subject of research since sustainable development itself is a controversial subject. It is seen that the personal and social developments of students in the curriculum of physical education are handled as two sides of the same coin. For this reason, teachers' perspectives are important in terms of the development of sustainability in sports and its transfer to young generations. The aim of this study is to examine the perspectives of physical education teachers, who are an important factor for the development of sustainability in sports. The sample of the study consists of 232 physical education teachers working in secondary and high schools in the city center of Kahramanmaraş in the 2019-2020 academic year. As data collection tools, the "“Sustainability in Sports Scale (SSS)"” developed by Koçak et. al. (2013). In statistical 
analysis; $T$ test was used for paired comparisons and one-way analysis of variance (ANOVA) was used for multiple comparisons $(\mathrm{p}<0.05)$. When the results of the study are examined, when the whole SSI $(=3.56$ \pm ,32) and its sub-dimensions are examined, the lowest attitude score is in the economic dimension $(\chi=$ $3.09 \pm, 52)$ and the highest attitude score is in participation sustainability $(=4.56 \pm, 59)$. These values show that teachers have a positive attitude in the whole of SSS and in individual, participation, organizational and environmental sustainability sub-dimensions, and they show a moderate sustainability attitude in social and economic sustainability sub-dimensions. As a result of the study, it can be said that male teachers are more sensitive to the importance of social sustainability, which includes the protection of rights and freedoms, social justice and political accountability. At the same time, it can be said that they think that it is an important dimension in terms of minimizing resource consumption, which includes the environmental sustainability dimension, ensuring the recycling of waste by reusing it, and generating renewable and non-polluting energy resources, leaving a more livable and sporting environment for future generations. Among the studies in the literature, Demirel (2009) and Fransson and Garling (1999) found in their studies that the sensitivity of women towards environmental attitude was higher than that of men. In addition, in the study of Deniş and Genç (2007), it was found that female university students' attitudes towards environmental sustainability were more positive than male students. These results contrast with our study findings. As another result of the study, the perceptions of the teachers who are older in the dimension of organizational sustainability in sports are higher than the younger ones. In the study conducted by Yücel, (2018) and Koçak (2013), no significant difference was found between the students' attitudes towards sustainability in sports according to the age variable. Teachers' sustainability attitudes in sports were found to be higher in the social sustainability sub-dimension of the teachers engaged in team sports compared to the participants who deal with individual sports. In the study conducted by Koçak (2013), no difference was found between the students' branches and their attitudes towards sustainability in sports. As another result of the study, it was found that teachers who have 16 years and more professional experience of sustainability attitudes in sports have high individual sustainability attitudes. Individual sustainability is defined as creating long-term changes in individuals' attitudes, abilities and / or behaviors through their participation in sports (Lindsey, 2008, p. 289). Individual Sustainability can be said to be the most important aspect of sustainability in sports because they experience these sub-themes more thanks to their professional experiences, and they emphasize the importance of individual sustainability themes since they are individuals who work one-on-one with children and young people in the field of physical education and sports. As a result, physical education teachers, who are the first practitioners of the development of sustainability in sports in the society, are pioneers in raising awareness, and it is important in terms of increasing the sensitivity of future generations. Adding lessons and subjects for the sustainable use of resources in the physical education curriculum will increase the awareness, attitude and behavior levels of teachers towards sustainability and increase their awareness and sensitivity to their students on this issue. For this reason, it can be said that education is one of the most important factors in removing the obstacles to sustainability in sports. Future research should focus on the sports organizations' expectations for sustainability in sports of the various stakeholder groups of sport. At the same time, trainings on sustainable development should be included in in-service training seminars organized for teachers. 